\title{
Verification of Enhanced Dynamic Torque per Ampere Capability in Saturated Induction Machines
}

\author{
Ian T. Wallace, Donald W. Novotny, Fellow, IEEE, Robert D. Lorenz, Senior Member, IEEE, \\ and Deepakraj M. Divan, Senior Member, IEEE
}

\begin{abstract}
An easily implemented technique for dynamic torque per ampere enhancement under high levels of motor saturation is described and validated via substantial experimental results presented in this paper. A saturation model assuming only $d$-axis saturation is utilized in field oriented control of the experimental system and the results are compared to theoretical predictions based on the same saturation model. In order to help users optimize this technique, the paper discusses motor selection issues for the production of this dynamic torque enhancement. An experimental illustration of the use of the torque enhancement principle to break away a load with high static friction is presented to demonstrate the practical application of the concept. Measurement methods used to evaluate the dynamic properties of the electromagnetic torque are presented in sufficient detail that users have appropriate tools for performing such work.
\end{abstract}

\section{INTRODUCTION}

A METHOD for increasing the dynamic torque per ampere capability of induction machines based on the use of indirect field orientation was presented in [1]. Under a fixed current limit, imposed by the switch ratings of the inverter, dynamic torque enhancement can be achieved by utilizing the dynamic properties of the machine. The flux, for instance, is related to the current by a first-order lag relationship. This occurs because of induced currents in the rotor, which support the flux. Thus, flux will exist in the machine for a period of time even after the flux producing $d$-axis current is completely removed. While the flux is still present, the inverter can apply its full current capability to the torque producing $q$-axis. The interaction of this temporarily large magnitude of $q$-axis current with the temporarily large magnitude of rotor flux produces torque greater than the optimal steady-state torque where current is being partitioned between the $d$-and $q$-axes [2]-[11].

To maximize the dynamic torque per ampere improvement using this method, it is necessary to operate with a

Paper IPSCD 94-31, approved by the Electric Machines Committee of the IEEE Industry Applications Society for presentation at the 1992 Industry Applications Society Annual Meeting, Houston, TX, October 4-9. This work was supported by the Wisconsin Electric Machines and Power Electronics Consortium (WEMPEC) of the University of Wisconsin-Madison. Manuscript released for publication February 25, 1994.

The authors are with the Department of Electrical and Computer Engineering, University of Wisconsin-Madison, Madison, WI 53706.

IEEE Log Number 9404068. large flux, thus driving the machine into saturation. Also, since the flux is dynamically varying in amplitude, it must be accurately tracked to ensure that field orientation is still achieved [12]. The saturation model, which predicts the level of flux, is therefore important [13]-[16]. This paper will present a saturation model which was used in both simulations and in experiments. The correlation of the theoretical and empirical results verify the validity and accuracy of the saturation model for the purpose of torque enhancement during flux transients.

The results will compare the electromagnetic torque produced using trapped rotor flux to enhance the dynamic torque per ampere with the optimal steady-state torque. These empirical results will be compared with theoretical and simulation results.

The measurement of electromagnetic torque is always difficult, especially where the torque is dynamically varying. One method of accurately estimating the transient electromagnetic torque is to measure the acceleration of the machine with no load attached. A software acceleration observer, which estimates the acceleration from measured position information, was implemented for that purpose. This paper will also discuss observer implementation issues, which include eigenvalue design and performance limitations and sensitivities.

\section{TORQue PER AMPERE Optimization}

\section{A. Field Orientation Induction Motor Model}

The model of a current fed induction machine is simplified under field orientation. By aligning the rotor flux $\lambda_{q d r}^{e}$ completely with the $d$-axis, the synchronous frame motor equations become

$$
\begin{gathered}
0=r_{r} i_{d r}^{e}+p \lambda_{d r}^{e}, \\
\lambda_{d r}^{e}=L_{m} i_{d s}^{e}+L_{r} i_{d r}^{e}, \\
\lambda_{q r}^{e}=L_{m} i_{q s}^{e}+L_{r} i_{q r}^{e}=0, \\
T_{e}=\frac{3}{2} \frac{P}{2} \frac{L_{m}}{L_{r}} \lambda_{d r}^{e} i_{q s}^{e}, \\
\omega_{s}=\frac{L_{m}}{\tau_{r}} \frac{i_{q s}^{e}}{\lambda_{d r}^{e}} .
\end{gathered}
$$


These equations must be used to develop the field orientation constraints during transient and steady-state optimization of the machine's torque per ampere relationship.

\section{B. Steady-State Optimization}

The current ratings of the inverter and the motor limit torque production in the steady state. The steady-state relationships are found by applying the steady-state condition, $p \lambda_{d r}^{e}=0$, to (1) and (2),

$$
\lambda_{d r}^{e}=L_{m} i_{d s}^{e},
$$

and steady-state torque becomes

$$
T_{e}=\frac{3}{2} \frac{P}{2} \frac{L_{m}}{L_{r}} i_{d s}^{e} i_{q s}^{e}
$$

From (7), it is clear that both of the inverter-supplied components, $i_{d s}^{e}$ and $i_{q s}^{e}$, of stator current produce steady-state torque. To maximize the torque per ampere under a stator current limit (i.e., a maximum value of $i_{q d s}^{e}$ ), the optimum partitioning of $i_{d s}^{e}$ and $i_{q s}^{e}$ must be found, where

$$
\left(i_{d s}^{e}\right)^{2}+\left(i_{q s}^{e}\right)^{2}=\left(i_{q d s}^{e}\right)^{2} .
$$

In a nonsaturated machine, the maximum torque per ampere occurs for $i_{d s}^{e}=i_{q s}^{e}=0.707 \cdot i_{q d s}^{e}$. However, when the saturation properties of the motor are included, the optimal ratio of $i_{d s}^{e}$ and $i_{q s}^{e}$ is altered by the nonlinear relationship between $i_{d s}^{e}$ and $\lambda_{d r}^{e}$. Fig. 1 shows the steadystate torque for a saturating machine with varying partitioning of three different stator current amplitudes [14]. By including the saturation effects of the motor, the optimal ratio of $i_{q s}^{e} / i_{q d s}^{e}$ increased over the unsaturated case. The peak torque for the machine running at 1.5 times rated stator current was reached at $i_{q s}^{e}=0.87^{*} i_{q d s}^{e}$. This shift occurs because, when saturated, increasing $i_{d s}^{e}$ produces smaller and smaller flux gains, reducing its effect on torque production. As a result, the stator current is worth more to torque production in the $q$-axis than in the $d$-axis. Therefore steady-state torque, under a stator current limit, is optimized by supplying a larger percentage of the stator current to the $q$-axis [14].

\section{Transient Optimization}

The rotor flux in the steady state, as defined by (6), is solely dependent on $L_{m}$ and $i_{d s}^{e}$. However, the general relationship for $\lambda_{d r}^{e},(2)$, which accounts for the dynamic case, shows that the rotor flux is supported by both the rotor and stator $d$-axis currents. The rotor current $\left(i_{d r}^{e}\right)$, however, is not supplied by the inverter but rather is an induced current. It will be shown that a change in the flux command $i_{d s}^{e}$ induces the transient rotor current $i_{d r}^{e}$, which decays with the rotor open circuit time constant and restricts the instantaneous change of rotor flux. It is this induced transient current which supports the rotor flux, and allows for dynamic torque production greater than previously attainable optimal steady-state torque.

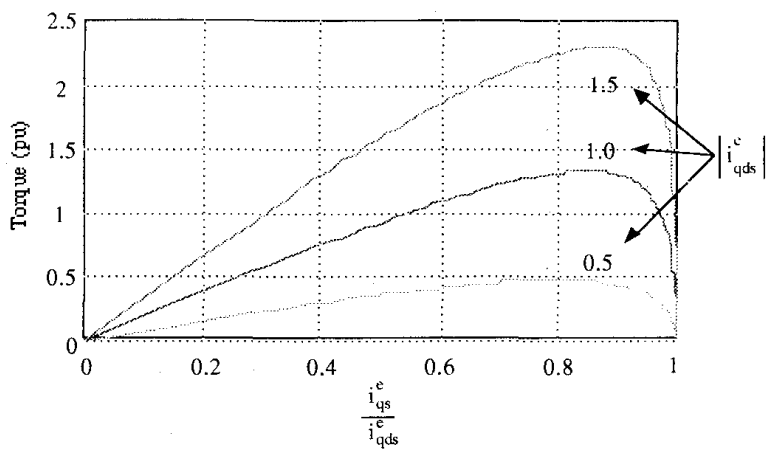

Fig. 1. Steady-state torque of a saturating field oriented induction machine as a function of the percentage of torque axis current for three different stator current levels.

1) Transient Rotor Current: The relationship between stator and rotor $d$-axis currents can be found from (1) and (2) as

$$
i_{d r}^{e}=\frac{-L_{m} p}{L_{r} p+r_{r}} i_{d s}^{e}, \quad \text { with } \tau_{r} \equiv \frac{L_{r}}{r_{r}} .
$$

The steady-state relationship $i_{d r}^{e}=0$ is reached when $p i_{d s}^{e}=0$. However, dynamically, the rotor current is proportional to the rate of change in the $d$-axis stator current ( $p i_{d s}^{e}$ ). That is, in response to a change in $i_{d s}^{e}$, an opposing $i_{d r}^{e}$ is induced to restrict the change, and decays exponentially with the rotor open circuit time constant $\tau_{r}$. It is this induced rotor current which initially retards the decay of the flux $\lambda_{d r}^{e}$.

2) Transient Rotor Flux: Rotor flux is supported by a steady-state current $\left(i_{d s}^{e}\right)$ and an induced transient current, which ensures the continuity of flux $\left(i_{d r}^{e}\right)$. Since a current regulator can only effect $i_{d s}^{e}$ directly, (1) and (2) can be solved for the dynamic flux response to $i_{d s}^{e}$ :

$$
\lambda_{d r}^{e}=\frac{L_{m}}{\tau_{r} p+1} i_{d s}^{e}
$$

This illustrates that $\lambda_{d r}^{e}$ is related to $i_{d s}^{e}$ by a first-order lag and that if $i_{d s}^{e}$ is completely removed, a decaying amplitude of flux will exist in the machine. The flux would be effectively trapped in the rotor by the induced rotor current, $i_{d r}^{e}$.

3) Optimizing Dynamic Torque Per Ampere: The concept of trapped rotor flux can be used to increase the transient torque per ampere capability of the machine above its optimal steady-state torque per ampere. In the steady state, peak torque production came from optimally partitioning $i_{q d s}^{e}$ into $i_{d s}^{e}$ and $i_{q s}^{e}$. In the dynamic case, the trapped flux acts as an independent, albeit decaying, flux source if the $d$-axis stator current support $i_{d s}^{e}$ is reduced or removed. Therefore, the unused $i_{d s}^{e}$ part of the stator current vector can be applied to increase $i_{q s}^{e}$ and thus increase torque production.

A possible scheme of controlling $i_{q s}^{e}$ and $i_{d s}^{e}$ to maximize transient torque per ampere under a stator current amplitude limit is as follows: 
1) Use all the available stator current in the $d$-axis to build up rotor flux.

2) When peak torque is required, switch all of the available stator current to the $q$-axis.

The interaction of the larger $i_{q s}^{e}$ and instantaneously unchanged rotor flux will produce an initial torque that is larger than the optimal steady-state torque. This torque will decay in amplitudes as the rotor flux decays.

\section{Flux Estimation}

The method of utilizing trapped rotor flux to maximize the torque per ampere of an indirect field oriented induction machine requires that the amplitude and location of the dynamic flux be known to ensure correct field orientation. The slip relationship (5) shows the amplitude of $\lambda_{d r}^{e}$ is used to meet the field orientation relationship.

Maximizing the transient torque per ampere involves supplying all the current available from the inverter to the $d$-axis, where the inverter is typically rated for 1.5 to 2.0 times the motor rated current. Since rated $i_{d s}^{e}$ for an induction motor is approximately 0.3 to 0.5 times its rated current, the machine will be significantly saturated during this process.

Since it is necessary to track the dynamic flux amplitude for indirect field orientation, a saturation model for the flux resulting from the increased $d$-axis current is also required.

\section{A. Saturation Model}

The goal of the saturation model is to aid in accurately predicting the magnitude of the dynamic flux, in order to maintain the correct slip frequency and ensure field orientation. Since field orientation control provides flux only in the $d$-axis, it can be assumed that saturation only occurs in the $d$-axis. As a result, the $q$-axis parameters in the slip frequency equation (11) do not vary with $\lambda_{d r}^{e}$. However, $d$-axis parameters $L_{m d}$ and $\tau_{r d}$ in the rotor flux equation (12) will be a function of the flux:

$$
\begin{gathered}
\omega_{s}=\frac{L_{m q}}{\tau_{r q}} \frac{i_{q s}^{e}}{\lambda_{d r}^{e}}, \quad \text { with } \tau_{r q}=\frac{L_{r q}}{r_{r}}, \\
\lambda_{d r}^{e}=\frac{L_{m d}}{1+p \tau_{r d}} i_{d s}^{e}, \quad \text { with } \tau_{r d}=\frac{L_{r d}}{r_{r}} .
\end{gathered}
$$

A two-step process was needed to experimentally find the relationship between $L_{m d}$ and $\lambda_{d r}^{e}$. The experimentally found saturation curve shown in Fig. 2 provides the relationship between $\lambda_{d r}^{e}$ and $i_{d s}^{e}$. Fig. 3 shows the relationship between $L_{m d}$ and $\lambda_{d r}^{e}$, which was determined from Fig. 2.

\section{B. Dynamic Flux Estimation}

The saturation model, which assumes ideal field orientation and hence only $d$-axis saturation, is used to track the amplitude of the dynamically varying flux. Typical indirect field orientation schemes which operate with a constant steady-state flux amplitude can implement (5)

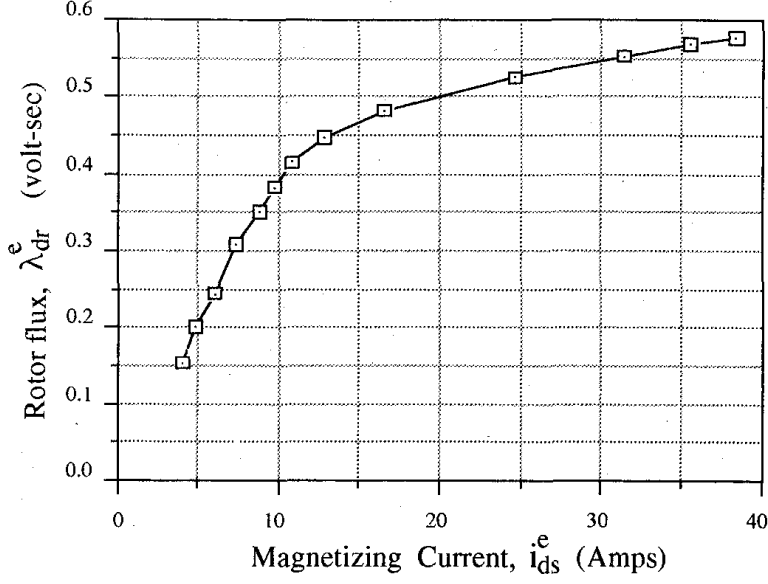

Fig. 2. Flux $\lambda_{d r}^{e}$ as a function of magnetizing current $i_{d s}^{e}$.

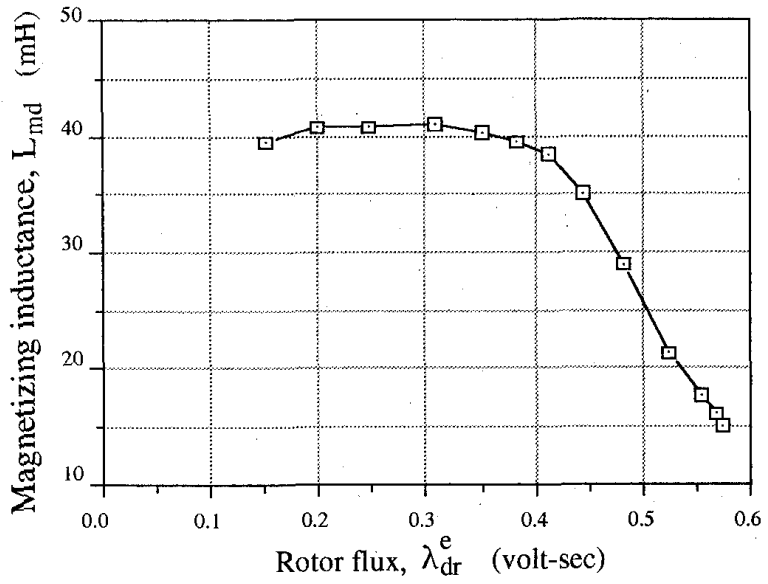

Fig. 3. Magnetizing inductance $L_{m d}$ as a function of flux $\lambda_{d r}^{e}$.

simply by incorporating $\lambda_{d r}^{e}$ together with $L_{m d}$ and $\tau_{r d}$ as in (13):

$$
\omega_{s}=K \cdot i_{q s}^{e} .
$$

However, when rotor flux is not constant and varies significantly into saturation, as in this case, a method to estimate its amplitude must be used to ensure field orientation. Since the inverter controls $i_{d s}^{e}$, the simplest estimation scheme would be to implement (12), which gives $\lambda_{d r}^{e}$ as a function of $i_{d s}^{e}$. That is, use the dynamic flux equation as an open-loop flux estimator. The parameters $L_{m d}$ and $\tau_{r d}$ and their dependence on rotor flux amplitude must be known. Therefore, the saturation model captured in Fig. 3 can be used to supply the experimentally determined relationship between $L_{m d}$ and $\lambda_{d r}^{e}$ which is unique to the machine being controlled.

A simple open-loop flux estimation scheme is inherently dependent on varying parameters such as the saturating inductance $L_{m d}$. However, while this open-loop topology is most parameter sensitive during motor saturation, indirect field orientation is insensitive, making it a simple and effective choice of implementation [1]. 
In order to implement this flux estimation in a digital system, the dynamic flux model, (12), was discretized using a first-order difference equation approximation as follows:

$$
\begin{aligned}
\lambda_{d r}^{e}[k]=L_{m d}\left(1-e^{-\Delta T / \tau_{r d}}\right) i_{d s}^{e}[k-1] & \\
& +e^{-\Delta T / \tau_{r d}} \lambda_{d r}^{e}[k-1] .
\end{aligned}
$$

\section{High-Performance Electromagnetic Toroue MEASUREMENT Via ACCELERATION ESTIMATION}

Measurement of dynamic torque enhancement is made difficult by the fact that the electromagnetic torque is not a directly measurable variable. Thus some form of alternative technique must be employed. One technique is to measure the motion response of the rotor alone and to deduce the applied electromagnetic torque based on accurate knowledge of the rotor's mechanical parameters. Such a technique would lend itself to verification of drive performance prior to its attachment to the load. It is this approach which is the subject of this section.

Machine rotors not connected to loads would be expected to act as inertial loads with only modest losses due to windage and bearing losses. From Newton's law, the electromechanical state equation is

$$
J \frac{d \omega_{r}}{d t}=\tau_{\mathrm{em}}-\tau_{w}-\tau_{b}
$$

where

$$
\begin{aligned}
J & =\text { rotor's polar moment of inertia, } \\
\omega_{r} & =\text { rotor speed, } \\
\tau_{\mathrm{em}} & =\text { electromagnetic torque, } \\
\tau_{w} & =\text { windage torque, } \\
\tau_{b} & =\text { bearing drag torque. }
\end{aligned}
$$

If the windage and bearing drag torques are negligible, then the electromechanical state equation may be approximated as

$$
J \frac{d \omega_{r}}{d t} \approx \tau_{\mathrm{em}}
$$

Thus, for machines not connected to loads, it is possible to directly measure the electromagnetic torque by measuring angular acceleration and scaling it by the rotor's polar moment of inertia, $J$.

The practical difficulty with such an approach is that general purpose angular accelerometers are not readily available. Furthermore, most machines used in modern drives already have digital position feedback transducers mounted, i.e., either optical encoders or electromagnetic resolvers. Thus, to obtain acceleration measurements, some form of estimation technique must be used. The most common techniques use numerical differentiation or acceleration observers [18], [19].

Numerical differentiation of digital position data appears to be a simple and direct way to calculate the acceleration. The problem is that the discretization of both angular position and time cause significant resolution quantization problems. The basic angular acceleration resolution quanta are

$$
\Delta \dot{\omega}_{\mathrm{res}}=\frac{\Delta \theta_{\mathrm{res}}}{\Delta T^{2}}
$$

which for a 2048 PPR encoder with $4 \times$ interface, and a $2-\mathrm{kHz}$ sample rate produces a basic angular acceleration resolution of

$$
\Delta \dot{\omega}_{\mathrm{res}}=\frac{\frac{1}{2048 \cdot 4}}{(0.0005)^{2}} \frac{\mathrm{rad}}{\mathrm{sec}^{2}}=488 \frac{\mathrm{rad}}{\mathrm{sec}^{2}}
$$

which represents a resolution of only about 1:60 for a typical servomotor with a peak acceleration capability of about $30,000 \mathrm{rad} / \mathrm{sec}^{2}$. This is very coarse resolution and extreme filtering would be needed to reduce the quantization noise. Such filtering would, of course, not be suitable for measurement of dynamic torque properties and thus numerical differentiation is not a good candidate for dynamic torque measurement.

Acceleration observer designs have been developed which are suitable for such measurement needs. It has further been demonstrated that such observers intrinsically provide signal response which is essentially instantaneous and that their resolution is determined by the precision of the calculations internal to the observer. This encoder-based acceleration observer topology is shown in Fig. 4 [18], [19].

The observer in Fig. 4 is comprised of two cascaded observers, first a velocity observer and second an acceleration observer. Each observer can be broken down into two main parts: feedforward and feedback. The feedforward part consists of a real-time simulation of the motor, which receives its input from the torque producing current command which is fed forward. This simulation runs in parallel with the actual system and can be thought of as an open-loop estimation of the motor's actual behavior. The accuracy of this part of the observer is totally dependent on the torque command feedforward and the inertia estimate $\hat{J}$. The feedback part consists of the closed-loop controller which uses the measured position $\theta$ as the reference and the estimated position $\hat{\theta}$ as the feedback signal. Within the eigenvalues (bandwidth) of the closedloop observer, the sensitivity to parameter errors is greatly reduced for this topology of observer. Above the eigenvalues (bandwidth) of the closed-loop observer, the estimates are primarily determined by the feedforward part and thus parameter sensitivity is degraded. Thus, it is best to optimize the bandwidth of this observer so as to reduce parameter sensitivity [17]-[19].

The following sections will discuss the implementation issues for acceleration observers, such as gain/bandwidth 


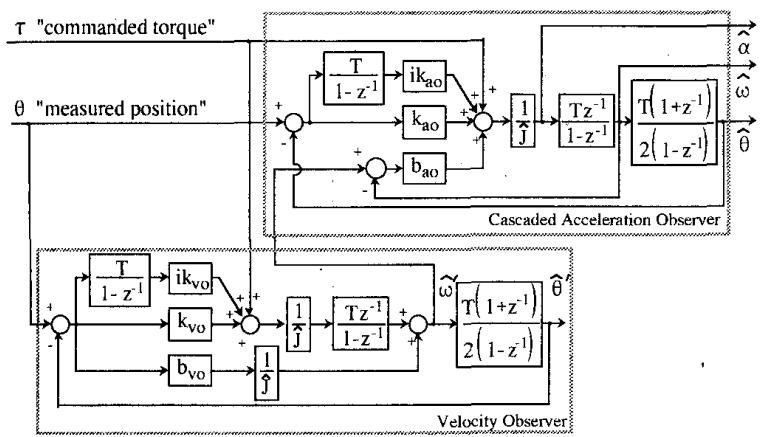

Fig. 4. Acceleration observer block diagram in discrete time format.

selection, as affected by sampling frequency and system element performance limitations.

\section{A. Gain / Eigenvalue (Bandwidth) Design}

Section of the appropriate eigenvalues (bandwidth) and calculation of the corresponding gains are important to obtaining accurate and reliable results from the observer. The lower the bandwidth of the observer, the more the observer will be dependent on the parameter sensitive command feedforward part. Therefore, a goal in designing the gains for the observer is to have large enough eigenvalues (high enough bandwidth) to overcome parameter errors. However, there is a limit on the magnitude of the gains (and thus bandwidth) due to the quantized encoder position information. As eigenvalues are increased, noise response due to encoder quantization increases. Hence, there is an inherent design trade-off in how high the bandwidths should be. One additional design decision is the selection of sampling frequency. Lowering the sampling frequency will reduce noise on the estimated velocity and acceleration signals. However, the maximum bandwidth will be compromised if the sampling frequency is low. This is because the sampling frequency establishes the upper limit on the possible bandwidth of the observer.

As a practical compromise with the quantization noise, the velocity portion of the observer was tuned for eigenvalues at 2,18 , and $170 \mathrm{~Hz}$ and the cascaded acceleration portion was tuned for eigenvalues at 1,10 , and $100 \mathrm{~Hz}$.

\section{B. Mechanical Integrity}

Ideally, the useful acceleration observer bandwidth (and thus parameter sensitivity) is limited only by the quantization (resolution) of the position feedback device. In practice, however, any other issues causing degradation of the feedback transducer measurements will also restrict the design limits. For example, harmonic errors due to misalignment between the encoder shaft and the motor produce harmonic relative motion (kinematic) errors on the encoder signals. These harmonic position errors will cause the acceleration observer to produce very large accelerations due to the frequency-squared relationship between position and acceleration harmonics. This contamination corrupts the observer estimates and thus must be appro- priately minimized. Such concerns should include both kinematic motion errors and structural mounting resonances and resulting dynamic motion errors.

\section{EXPERIMENTAL RESULTS}

\section{A. System Implementation}

Indirect field orientation control of the induction machine with dynamic torque per ampere enhancement was implemented using the DSP-based system shown schematically in Fig. 5. This differs from normal indirect field orientation control by the dynamic flux estimation. The motor in Appendix B was driven by a $6-\mathrm{kHz}$ current regulated PWM inverter (CRPWM). It was controlled by a DSP-based, indirect field oriented controller. The DSP system also acted to perform the dynamic torque enhancement method described in Section II-C. 3 and to execute the cascaded acceleration observer described in Section IV. The maximum current from the inverter was set to 1.5 times the motor rated current ( $1.5 \mathrm{pu} i_{q d s}^{e}$ ).

\section{B. No-Load Acceleration.}

1) Tuned Field Orientation: The dynamic torque enhancement method of Section II-C.3 was applied to the unloaded test motor which was initially at standstill. By using $1.5 \mathrm{pu} i_{q d s}^{e}$ to build up the flux and then switch it to the $q$-axis, a peak acceleration of $3,045 \mathrm{rad} / \mathrm{sec}^{2}$ was reached, corresponding to a torque of $3.0 \mathrm{pu}$. Since the optimal steady-state torque for this machine is $2.3 \mathrm{pu}$, the torque enhancement technique yielded a $30 \%$ improvement in torque. Fig. 6(a) shows the measured acceleration is only very slightly less than the theoretical acceleration for tuned operation. The theoretical acceleration calculations were based on the same saturation model used in the implementation. The results indicate that an open-loop flux estimator which incorporates measured saturation data can be used to successfully field orient a saturated induction machine, even during substantial flux dynamics.

As expected, the acceleration decays from its initial peak in accordance with the rotor time constant. Once the rotor flux decays to the level required for optimal steadystate torque, the motor is provided with the constant $i_{d s}^{e}$ and $i_{q s}^{e}$ required for that torque output. This corresponds to the constant acceleration seen in Fig. 6(a).

2) Detuned Field Orientation: It was shown through simulations in [1] that indirect field orientation control under conditions of saturation is actually highly insensitive to detuning. Fig. 6(b) shows the measured acceleration for a slip constant which is two times the correct value. These data are overlaid with the acceleration theoretically expected for correct tuning. The large $\omega_{s}$ demagnetized the $d$-axis, causing the flux to decay more quickly. This is visible in Fig. 6(b), where the measured acceleration decays more quickly than the theoretical. However, the relative agreement demonstrates the insensitivity of this method to detuning of the field oriented controller. It should also be noted that the peak torque obtained is not affected by the detuning [1]. This would be expected since the zero-speed initial conditions guaranteed initial orthog- 


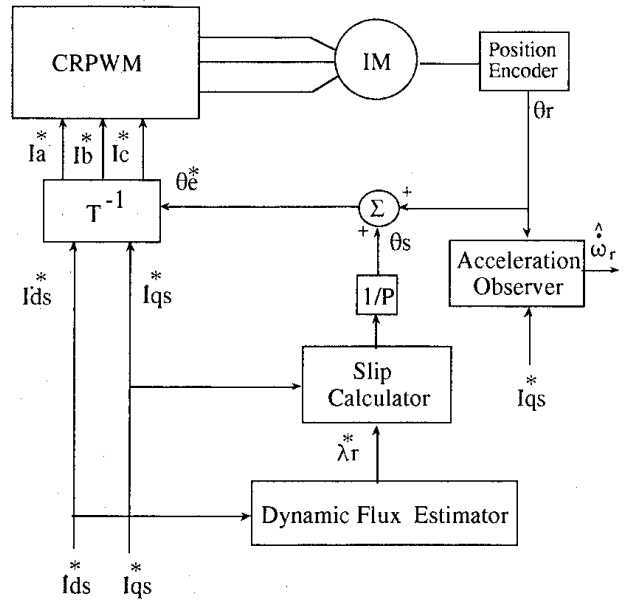

Fig. 5. Block diagram of an indirect field orientation controller, with flux estimator.

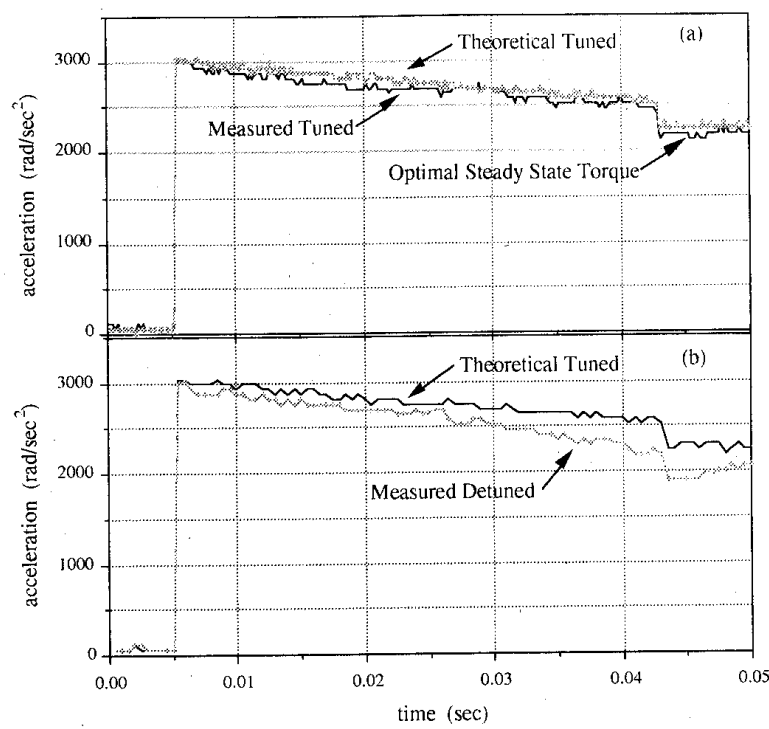

Fig. 6. (a) No-load acceleration with tuned field orientation. (b) No-load acceleration with detuned field orientation. $L_{m q} / \tau_{r q}=2 \cdot L_{m q} / \tau_{r q}$, i.e., slip constant was $2 \times$ actual.

onal alignment of the flux and mmf at the start of the acceleration.

\section{Breaking Away A High-Stiction Load}

One of the most suitable applications of this technique is for breaking away a load with high stiction. For cases where the optimal steady-state torque of the motor is not enough to break the motor free, this method may provide a solution which does not require an oversized motor. Also, since the motor is at standstill, with zero back emf, the inverter will have ample voltage to build up the flux. Once the stiction load has been overcome by the increased torque per ampere and the motor is up to speed, the drive would return to normal operation.
To test this concept, the shaft ends of a 10-hp four-pole induction motor were attached to an electromagnetic brake and to a resolver for position and speed feedback. The friction force obtained from the brake mimics a stiction load at zero speed and acts like a combination of Coulomb and viscous drag at speeds after breakaway. The goal of this test was to demonstrate that a load which cannot be started with optimal steady-state torque, can be started using the enhanced torque per ampere method.

Fig. 7 shows the torque command and rotor speed results from the test. The data show how, after the current was switched to the $q$-axis, producing the enhanced peak torque, the motor was able to overcome the brake friction and accelerate. However, as the flux and torque decayed to the optimal steady-state level, the torque dropped below the brake torque. As a result, the net negative torque decelerated the rotor back to standstill. the measured rotor speed in Fig. 7 was obtained from the $\mathrm{R} / \mathrm{D}$ converter velocity output signal.

There are several interesting caveats in the data. First, the noise on the $R / D$ velocity signal measurement was not related to actual torque (and acceleration) in the motor, but rather it correlated to the carrier demodulation noise of the converter. Thus, filtering was applied as shown to remove some of those artifacts. Of more general concern than the $\mathrm{R} / \mathrm{D}$ noise is the large oscillations of the rotor speed immediately after the peak torque was applied. This was caused by the low-stiffness wooden platform on which the motor stator and electromagnetic brake were mounted. The initial peak torque caused a windup of the platform which then broke loose when the stiction torque was overcome by the motor. The oscillation shows the damping of the energy stored in the platform windup up to the point of breaking loose. While this interaction is specific to this system, the same type of compliance and oscillation may well be present in other such high-stiction apparatus. It should be noted that the low pass filtered velocity signal obscures the actual nature of the breakaway oscillation.

\section{Motor Selection Criterion}

A method for improving the dynamic torque per ampere capability in induction machines has been experimentally verified, including the effect of saturation. However, the motor properties which enhance its capability must also be identified for this technique to become generally useful in drive system design. The following section helps to identify which type of machine will yield the best results.

The torque enhancement technique is a two-stage operation that takes advantage of high initial flux levels as well as large currents supplied to the $q$-axis. Large initial flux is achievable in machines which normally operate at levels well below the knee of the saturation curve. Thus, for example, high-efficiency machines are well suited since they can reach flux levels of $1.5 \mathrm{pu}$, or more if full current is used for initial magnetization. Another aspect of the torque improvement comes from the switching of large 


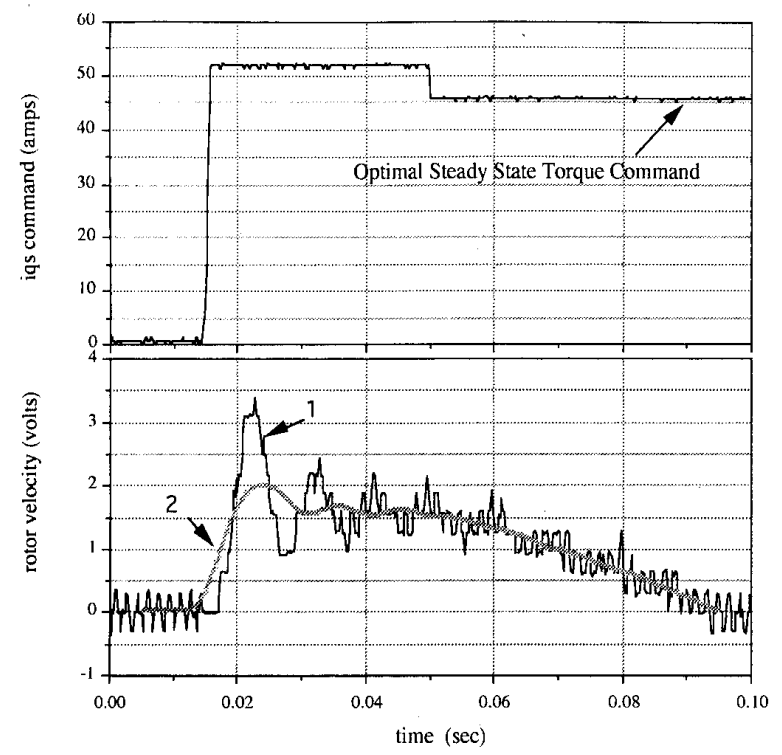

Fig. 7. Rotor velocity $\omega_{r}$ and torque command $i_{q s}^{e}$. (1) = measured rotor speed, $(2)=$ filtered rotor speed $(300 \mathrm{rpm}=8 \mathrm{~V})$.

currents to the $q$-axis. Torque gains, above optimal steady-state torque, will occur in machines with low $i_{q s}^{e} / i_{q d s}^{e}$ ratio, as shown in Fig. 1 . The lower the ratio at optimal steady-state torque, the larger the $i_{q s}^{e}$ gains will be during torque enhancement. A low $i_{q s}^{e} / i_{q d s}^{e}$ ratio is due to large saturated $L_{m d}$, therefore machines with large $L_{m d}$ during saturation are best suited for torque enhancement.

The amount of time that the enhanced torque is greater than the optimal steady-state torque is totally dependent on the rotor open circuit time constant. Therefore, it is again advantageous for the machine to have a large $L_{m d}$ and also low rotor resistance. The size of the machine is also important since, from experimental tests on highefficiency machines, the duration of the enhanced torque is approximately $30 \%$ of the rotor time constant. Therefore, as dictated by scaling laws, the greater in size and lower in pole number of the induction machine, the longer the rotor time constant and corresponding torque enhancement will be.

\section{ConClusion}

The flux dynamic and saturation models for utilizing trapped flux to increase the dynamic torque per ampere of a field oriented induction machine have been experimentally verified. The motor chosen for analysis yielded a $30 \%$ increase in dynamic torque over the best possible steadystate torque. Results show that this method is robust with respect to field orientation control parameters, since the peak torque attainable is unaffected and its decay rate is only marginally affected when detuned.

It has been demonstrated that such dynamic peak torque capability is useful in situations which require increased torque at start-up, for instance to break away large static friction loads. In such cases, it is possible to build up the flux before the peak torque is required. This solution capitalizes on unused dynamic capability of the inverter and machine, thus eliminating the need for equipment with higher ratings.

The machine properties that enhance this method have been identified. It is the large saturation flux density and $L_{m d}$ that increase the dynamic torque per ampere significantly above the optimal steady-state level. The rotor time constant determines the duration of the enhancement, hence, the machine's size and rotor design can be chosen to capitalize on this relationship.

It has been shown, through correlation of simulation and experimental results, that an open-loop flux estimator which uses measured saturation data successfully field orients the saturated machine.

The implementation of a high-performance transient electromagnetic torque measurement technique using an acceleration observer has been presented as a basic tool in verifying motor torque performance via no-load tests.

\section{APPENDIX A}

\section{Parameter Definitions}

$i_{q d s}^{e}$ Stator current vector in excitation frame.

$\lambda_{q d r}^{e}$ Rotor flux vector in excitation frame.

$L_{m}$ Mutual inductance.

$L_{r} \quad$ Rotor self-inductance.

$\tau_{r} \quad$ Rotor time constant.

$\omega_{s} \quad$ Slip frequency.

$p \quad$ Differential operator.

$P \quad$ Number of pole pairs.

$T_{e} \quad$ Electromagnetic torque.

$T_{L} \quad$ Load torque.

\section{APPENDIX B}

\section{Machine Parameters}

Gould Eplus Induction Motor, Frame F215T

$\begin{array}{ll}10 \mathrm{hp}, \quad 3 \varnothing & L_{m}=38.0 \mathrm{mH} \\ 230 \mathrm{~V} & L_{r}=39.5 \mathrm{mH} \\ 24.2 \mathrm{~A} & L_{s}=39.5 \mathrm{mH} \\ \text { 4-poles } & r_{r}=0.2 \mathrm{ohms} \\ J=.040 \mathrm{Kgm}^{2} & T_{e} \text { rated }=40.4 \mathrm{~N}\end{array}$

REFERENCES

[1] I. T. Wallace, D. W. Novotny, R. D. Lorenz, and D. M. Divan, "Increasing the dynamic torque per ampere capability of induction machines," Conf. Record IEEE LAS Ann. Mtg., 1991, pp. 14-20.

[2] R. D. Lorenz and S. M. Yang, "Efficiency-optimized flux trajectories for closed cycle operation of field oriented induction machine drives," IEEE Trans. Industry Applicat., vol. 28, no. 3, pp. 574-580, May/June 1992.

[3] A. Kusko and D. Galler, "Control means for minimization of losses in ac and dc motor drives," IEEE Trans. Industry Applicat., vol. IA-19, no. 4, pp. 561-570, July/Aug. 1983.

[4] D. S. Kirschen, D. W. Novotny, and.W. Suwanwisoot, "Minimization induction motor losses by excitation control in variable frequency drives," IEEE Trans. Industry Applicat., vol. IA-20, no. 5, pp. 1244-1250, Sept./Oct. 1984.

[5] S. K. Sul and M. H. Park, "A novel technique for optimal efficiency control of current source inverter fed induction motor," IEEE 1986 P.E.S.C., pp. 486-493. 
[6] J. M. D. Murphy and V. B. Honsinger, "Efficiency optimization of inverter-fed induction motor drives," Conf. Rec. 1982 IEEE LAS Ann. Mtg., pp. 544-552.

[7] R. M. Green and J. T. Boys, "Inverter ac-drive efficiency," IEE Proc., vol. 129, pt. B, no. 2, pp. 75-82, Mar. 1982.

[8] H. G. Kim, S. K. Sul, and M. H. Park, "Optimal efficiency drive of a current source inverter fed induction motor by flux control," IEEE Trans. Industry Applicat., vol. LA-20, no. 6, pp. 1453-1459, Nov./Dec. 1984.

[9] D. S. Kirschen, D. W. Novotny, and T. Lipo, "Optimal efficiency of an induction motor drive," IEEE Trans. Energy Conversion, vol EC-2, no. 1, pp. 70-76, Mar. 1987.

[10] D. S. Kirschen, "Optimal efficiency control of induction machines," Ph.D. thesis, Univ. Wisconsin-Madison, 1985.

[11] D. Galler, "Energy efficient control of ac induction motor vehicles," Conf. Rec. 1980 IEEE LAS Ann. Mtg., pp. 301-308.

[12] R. D. Lorenz and S. M. Yang, "AC induction servo sizing for motion control applications via loss minimizing real-time flux control," IEEE Trans. Industry Applicat., vol. 28, no. 3, pp. 589-593, May/June 1992.

[13] P. L. Alger, Induction Machines, Their Behavior and Uses, 2nd ed. New York: Gordon \& Breach Science Publishers, 1970

[14] R. D. Lorenz and D. W. Novotny, "Saturation effects in field oriented induction machines," IEEE Trans. Industry Applicat., vol. 26, no. 2, pp. 283-289, Mar./Apr. 1990.

[15] J. E. Brown, K. P. Kovacs, and P. Vas, "A method of including the effects of main flux saturation in the generalized equations of ac machines," IEEE Trans. Power Appar. Syst., vol. PAS-102, no. 1, Jan. 1983.

[16] K. P. Kovacs, "On the theory of cylindrical rotor ac machines, including main flux saturation," IEEE Trans. Power Appar. Syst. vol. PAS-103, no. 4, Apr. 1984

[17] R. D. Lorenz and K. Van Patten, "High resolution velocity estimation for all digital, ac servo drives," IEEE Trans. Industry Applicat., vol. 27, no. 4, pp. 701-708, July/Aug. 1991.

[18] P. B. Scmidt and R. D. Lorenz, "Design principles and implementation of acceleration feedback to improve performance of dc drives," IEEE Trans. Industry Applicat., vol. 28, no. 3, pp. 594-599, May/June 1992.

[19] M. H. Moatemri, P. B. Schmidt, and R. D. Lorenz, "Implementation of a DSP-based, acceleration feedback controller," Conf. Rec 1991 IEEE IAS Ann. Mtg., pp. 1425-1430.

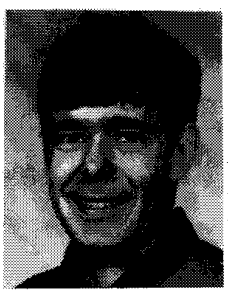

Ian T. Wallace received the B.S. degree in elec trical engineering from Pennsylvania State University in 1989. In 1992 he earned the M.S.E.E. degree from the University of Wisconsin-Madison, where he is presently a Ph.D. candidate.

Prior to entering graduate school he was employed as an electrical and manufacturing engineer by Ford Motor Company's Electronics Division. His research interests include power converters and the control of ac machines.

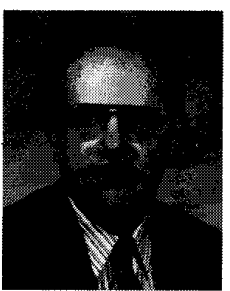

Donald W. Novotny (F'87) received the B.S. and M.S. degrees in electrical engineering from the Illinois Institute of Technology, Chicago, in 1956 and 1957, and the Ph.D. degree from the University of Wisconsin-Madison in 1961

Since 1961 he has been a member of the faculty at the University of Wisconsin-Madison, where he is currently Grainger Professor of Electric Machines and Power Electronics and Co-director of the Wisconsin Electric Machines and Power Electronics Consortium (WEMPEC). He served as Chairman of the Electrical and Computer Engineering Department from 1976 to 1980 and as an Associate Director of the University, Industry Research Program from 1972 to 1974 and from 1980 to the present. He has been active as a consultant to many organizations, including Marathon Electric Co., Borg Warner Corp., Barber Coleman Co., Otis Elevator Corp., Allen Bradley Co., Eaton Corporation, and the
Wisconsin Department of Natural Resources. He has also been a Visiting Professor at Montana State University, the Technical University of Eindhoven, Eindhoven, The Netherlands, the Catholic University of Leuven, Leuven, Belgium, and a Fulbright Lecturer at the University of Ghent, Ghent, Belgium. He has published over 90 technical articles on electric machines, variable frequency drives, and power electronic control of industrial systems, several of which have received prize paper awards from the IEEE Industry Applications Society.

Dr. Novotny is a member of IEEE, ASEE, Sigma Xi, Eta Kappa Nu, and Tau Beta Pi, and is a Registered Professional Engineer in Wiscon$\sin$.

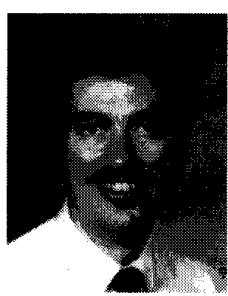

Robert D. Lorenz (SM'92) received the B.S. M.S., and Ph.D. degrees from the University of Wisconsin-Madison in 1969, 1970, and 1984, respectively.

Since 1984 he has been a member of the faculty of the University of Wisconsin-Madison, where he is Professor of Mechanical Engineering and of Electrical and Computer Engineering. In this position he acts as Associate Director of the Wisconsin Electric Machines and Power Electronics Consortium and as Co-Director of the Advanced Automation and Robotics Consortium. He was a Visiting Research Professor in the Electrical Drives Group of the Catholic University of Leuven, Leuven, Belgium and in the Electrical Drives Institute of the Technical University of Aachen, West Germany, in the summer of 1989 and the summers of 1987 and 1991, respectively. In 1969 1970 he did his Master thesis research at the Technical University of Aachen, West Germany. From 1972 to 1982 he was a member of the research staff at the Gleason Works in Rochester, New York. His current research interests include sensor integrated electromagnetic actuator technologies, real-time digital signal processing and estimation techniques, and ac drive and high-precision machine control technologies.

Dr. Lorenz is a Chairman of the IEEE IAS Industrial Drives Committee, and is a member of the Industrial Automation and Control Committee, the Electrical Machines Committee, and the Industrial Power Converter Committee. He is an active consultant to many organizations and is a Registered Professional Engineer in the States of New York and Wisconsin. He is a senior member of the IEEE, a member of the ASME the ISA, and the SPIE.

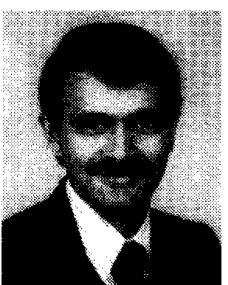

Deepakraj M. Divan (SM'92) received the B.Tech. degree in electrical engineering from the Indian Institute of Technology, Kanpur, India in 1975. He also received the M.Sc. degree - and the Ph.D. degree in electrical engineering from the University of Calgary, Calgary, Canada.

He worked for two years as a Development Engineer with Philips India Ltd. After finishing his Masters program in 1979, he started his own concern in Pune, India, providing product development and manufacturing services in the power electronics and instrumentation areas. In 1983, he joined the Department of Electrical Engineering at the University of Alberta as an Assistant Professor. Since 1985, he has been with the Department of Electrical and Computer Engineering at the University of Wisconsin Madison where he is presently a Professor. $\mathrm{He}$ is also an Associate Director of the Wisconsin Electric Machines and Power Electronics Consortium (WEMPEC), a group of approximately 48 industrial sponsors supporting research in the area of power electronics and machines. His primary areas of interest are in power electronic converter circuits and control techniques. He has over 60 papers in the area as well as 12 patents.

He was a recipient of the Killam Scholarship while in his Ph.D. program and has also won various prize papers including the IEEE-IAS Best Paper Award for 1988-89, second prize paper at PCC-Yokohama 93. prize papers for the Industrial Drives Committee in 1989 and 1991, the Industrial Power Converter Committee in 1983, 1989, and 1991, and the Power Semiconductor Committee in 1990. He is a consultant for 
various organizations including the Electric Power Research Institute and Oakridge National Laboratory, and is also working with severa industries. He has been the Program Chairman for the 1988 and 1989 Industrial Power Converter Committee of the IEEE-IAS, Transactions Review Chair for the committee in 1990 and 1991, and is presently Chairman of the Committee. He was Technical Program Chairman for
PESC 91, and a Treasurer for PESC 89. He was Chairman of the Education Committee in the IEEE Power Electronics Society during 1990 and 1991, and is presently the Technical Vice President for the society. He is a member of the R \& D Committee of the Power Sources Manufacturers Association and a member of the National Committee on Power Electronics. 